\title{
CARACTERIZAÇÃO SANITÁRIA E FÍSICO-QUÍMICA DE QUEIJO TIPO PARMESÃO RALADO COMERCIALIZADO EM MACEIÓ / AL
}

\section{ARTIGO ORIGINAL}

SOARES, Camila Conceição Luz¹, PEIXOTO, Isabela Braga², LUCENA, Sarah Regina da Silva ${ }^{3}$, OLIVEIRA, Vitória Lívia Marinho de ${ }^{4}$, PACHECO, Jamille Gonçalves $^{5}$, SOUZA, Eliane Costa ${ }^{6}$, SILVA, Vitor Luiz de Melo ${ }^{7}$

SOARES, Camila Conceição Luz. Et al. Revista Científica Multidisciplinar Núcleo do Conhecimento. Caracterização sanitária e físico-química de queijo tipo parmesão ralado comercializado em Maceió / AL. Ano 06, Ed. 04, Vol. 01, pp. 141-155. Abril. ISSN: 2448-0959, Link de acesso: https://www.nucleodoconhecimento.com.br/nutricao/parmesao-ralado, DOI: 10.32749/nucleodoconhecimento.com.br/nutricao/parmesao-ralado

\section{RESUMO}

O queijo é derivado do leite que tem sido apontado como um potencial transmissor de patógenos de origem alimentar devido suas características intrínsecas. Durante seu processamento, falhas nas etapas podem permitir o desenvolvimento e multiplicação de micro-organismos patogênicos como bactérias e fungos, além de suas toxinas. O presente estudo teve como objetivo caracterizar a qualidade sanitária e físico-química de queijos tipo parmesão ralado comercializado em supermercados em Maceió - AL. A metodologia consistiu na realização de uma pesquisa de campo, onde foram encontradas 13 marcas comerciais de queijo tipo parmesão ralado. As marcas comerciais foram adquiridas e transportadas ao

\footnotetext{
${ }^{1}$ Acadêmica do curso de Nutrição.

${ }^{2}$ Acadêmica do curso de Nutrição.

${ }^{3}$ Acadêmica do curso de Nutrição.

${ }^{4}$ Acadêmica do curso de Nutrição.

${ }^{5}$ Acadêmica do curso de Nutrição.

${ }^{6}$ Mestre em Nutrição Humana. Professora orientadora do curso de Nutrição do Cesmac/AL.

${ }^{7}$ Doutor em Medicina Veterinária. Professor coorientador do curso de Nutrição.
}

RC: 81950

Disponível em: https://www.nucleodoconhecimento.com.br/nutricao/parmesao-ralado 
laboratório multidisciplinar. As análises para Escherichia coli ocorreram pelo método dos tubos múltiplos, enquanto a técnica de semeadura de superfície foi utilizada para Stapylococcus coagulase positiva, bolores e leveduras. As análises de $\mathrm{pH}$ foram realizadas com o uso do potenciômetro e os teores de sódio foram obtidos através da leitura dos valores disponibilizados na rotulagem do produto. Os resultados demonstraram que as amostras não estavam contaminadas por Escherichia coli e bolores e leveduras, entretanto, 30,7\% das amostras apresentaram a presença do Staphylococcus coagulase positiva com valores acima do permitido pela legislação. Em relação aos valores de pH e sódio, o estudo encontrou uma variação de 5,14 - 5,61 e 45 a $623 \mathrm{mg} / 10 \mathrm{~g}$ respectivamente. A pesquisa considera que a contaminação microbiologia é limitada, porém, tem maior susceptibilidade ao crescimento por Staphylococcus sp., sendo preocupante, uma vez que esses micro-organismos produzem uma enterotoxina termoestável que pode acarretar intoxicação alimentar, o que representa um risco para saúde pública.

Palavras-chaves: Bactérias, Contaminação dos alimentos, Conservação de alimentos.

\section{INTRODUÇÃO}

O queijo tipo parmesão ocupa lugar de destaque no Brasil por ter vários empregos na culinária, sendo na maioria das vezes utilizado para consumo sem ser submetido a qualquer tipo de temperatura. É um produto muito comum na alimentação, abrangendo todas as classes sociais (JUSTUS et al., 2011). Além disso, o leite como sua matéria-prima é um alimento com alto teor de macromoléculas como proteínas carboidratos e lipídeos. Durante sua elaboração, ocorrem várias etapas de processamento até a obtenção do produto final. Portanto, qualquer falha em uma das etapas pode potencialmente oferecer riscos à saúde do consumidor (PIMENTEL et al., 2002).

Segundo Pinto et al. (2009) o queijo é o alimento mais associado a contaminações de origem biológica, sendo predominante a presença dos coliformes a $45^{\circ} \mathrm{C}$,

RC: 81950

Disponível em: https://www.nucleodoconhecimento.com.br/nutricao/parmesao-ralado 
Staphylococcus sp. e os bolores e leveduras. Os Staphylococcus sp., por serem residentes da microbiota das fossas nasais, garganta e pele da maioria dos seres humanos, quando são encontrados nos alimentos, são considerados indicadores de condições sanitárias inadequadas oriundas dos manipuladores. Além disso, o Staphylococcus coagulase positiva produz nos alimentos toxinas termoestáveis que ao serem ingeridas podem causar intoxicações alimentares (RIDEL, 2005).

A bactéria Escherichia coli por sua vez, é a principal representante do grupo de coliforme a $45^{\circ} \mathrm{C}$, sendo utilizada como indicadora de contaminação fecal. Algumas cepas dessa bactéria são enteropatogênicas, muito tóxicas e têm sido identificadas, de forma crescente, em vários surtos graves (MARTIN et al., 2016).

Em relação aos bolores, esses são facilmente encontrados em produtos alimentícios, especialmente em alimentos de baixa umidade como o queijo parmesão, que pela sua característica higroscópica, favorece o desenvolvimento desses micro-organismos. Além disso, podem produzir micotoxinas potencialmente citotóxicas, mutagênicas, teratogênicas e carcinogênicas (FRANCO; LANDGRAF, 2008).

A literatura cientifica descreve que os bolores, em sua maioria, quando encontrados em queijos como o parmesão, não são considerados patogênicos, causando no máximo alterações químicas e físicas. Entretanto, não pode ser considerada a exclusão da possibilidade do risco que pode provocar a saúde pública caso o crescimento microbiano destes seja exacerbado no alimento. Bolores da espécie Aspergillus flavus, os quais produzem a micotoxina (aflatoxina B1), já foram isolados em queijos (FURTADO, 2005).

Além da contaminação microbiológica, o potencial hidrogeniônico $(\mathrm{pH})$ é outro fator muito importante que influencia diretamente o crescimento dos micro-organismos nos alimentos, pois esses podem crescer ou serem inibidos em diversas faixas de pH (GERMANO; GERMANO, 2019).

RC: 81950

Disponível em: https://www.nucleodoconhecimento.com.br/nutricao/parmesao-ralado 
Sendo assim, faz-se necessário que as indústrias de alimentos obrigatoriamente adotem as Boas Práticas de Fabricação (BPF) para reduzir os riscos microbiológicos que estejam presentes e/ou que se desenvolvam durante a fabricação do produto, atingindo populações microbianas maiores do que as determinadas pela legislação, e consequentemente causar algum tipo de Doenças Transmitidas por Alimentos (DTAs) (HOFFMAN et al., 2004 e ABREU et al., 2010), que são causadas quando ocorre a ingestão de alimentos ou bebidas contaminadas com patógenos e/ou toxinas por eles produzidas, em quantidades que possam afetar a saúde do consumidor (FRANCO; LANDGRAF, 2008).

Portanto, a realização deste projeto torna-se importante, visto que, dentre os derivados lácteos mais consumidos no Brasil, o queijo tipo parmesão ralado se destaca pelo elevado consumo principalmente em decorrência do custo baixo e facilidade de obtenção. Esse alimento muitas vezes acompanha saladas, massas e sanduiches, sendo utilizado por todas as faixas etárias, desde crianças até idosos, que por sua vez já possuem um sistema imune fragilizado.

Em vista da possibilidade de obter e fornecer informações a população que consome o queijo tipo parmesão ralado no Brasil e dos possíveis perigos que esse pode ocasionar à saúde do consumidor, caso esteja contaminado por bactérias patogênicas, emerge a preocupação imediata com a qualidade microbiológica desse derivado lácteo comercializado em praticamente todos os estabelecimentos alimentícios.

Portanto, o objetivo desta pesquisa foi caracterizar a qualidade sanitária e físicoquímica do queijo tipo parmesão ralado comercializado na cidade de Maceió/AL.

\section{MATERIAL E MÉTODO}

A presente pesquisa trata-se de um estudo analítico experimental. Existem atualmente no comércio varejista de Maceió 13 marcas comerciais de queijo tipo

RC: 81950

Disponível em: https://www.nucleodoconhecimento.com.br/nutricao/parmesao-ralado 
parmesão ralado, essas foram identificadas por letras do alfabeto $(A, B, C, D, E, F$, G, H, I, J, K, L e M) objetivando manter a idoneidade de seus fabricantes.

As amostras foram adquiridas nos supermercados localizados em diversos bairros da cidade de Maceió/AL, em suas embalagens comerciais, contendo $50 \mathrm{~g}$ e dentro da data de validade. Foram transportadas em temperatura ambiente para o Laboratório multidisciplinar. As análises microbiológicas das amostras e do potencial hidrogeniônico $(\mathrm{pH})$ foram realizadas utilizando-se as técnicas recomendadas por Silva et al. (2017) e do Instituto Adolfo Lutz - IAL (1985). Para verificar o teor de sódio nas amostras, foi considerado o valor disponibilizado na rotulagem do produto.

No laboratório, a superfície externa da embalagem foi limpa com álcool $70 \%$ antes de ser aberta com um estilete estéril. Foi pesada assepticamente $25 \mathrm{~g}$ da amostra e transferida para um erlenmayer contendo $225 \mathrm{~mL}$ de solução salina estéril a 0,85\%. A partir deste homogeneizado (diluição $10^{-1}$ ), foi preparada a próxima diluição transferindo $1 \mathrm{~mL}$ para um tubo contendo $9 \mathrm{~mL}$ do mesmo diluente (diluição $10^{-2}$ ) e assim sucessivamente até a diluição $10^{-3}$.

\subsection{QUANTIFICAÇÃO DE ESCHERICHIA COLI.}

Após a diluição seriada realizada anteriormente, foram transferidos $1 \mathrm{~mL}$ de cada diluição $\left(10^{-1}, 10^{-2}\right.$ e $\left.10^{-3}\right)$ para 3 tubos contendo caldo Lauril Sulfato Triptose (LST), esses foram incubados a $3^{\circ} \mathrm{C}$ por 48 horas e, posteriormente dos tubos positivos, que continham gás no interior do tubo Durhan e turbidez do meio, foi transferida uma alçada para tubos contendo caldo Escherichia coli (EC) para confirmação de coliformes a $45^{\circ} \mathrm{C}$. Os tubos foram incubados em banho maria a $44,5^{\circ} \mathrm{C}$ durante 24 $h$, após esse tempo foram observados os tubos positivos (turvos e com gás nos tubos de Durhan). De cada tubo positivo do caldo EC foram semeadas, com a alça de platina, alíquotas em placas de ágar eosina-azul de metileno (EMB) e incubadas a 35ํㄷ/24 h. Após a incubação, foram selecionadas de cada placa três a cinco colônias típicas da bactéria Eschericha coli (de cor escura, chata, seca e com brilho metálico) e inoculadas em tubos com ágar nutriente inclinado e incubados a

RC: 81950

Disponível em: https://www.nucleodoconhecimento.com.br/nutricao/parmesao-ralado 
temperatura de $35^{\circ} \mathrm{C} / 24 \mathrm{~h}$. Após a incubação, as colônias foram semeadas em meios de cultura específicos para a identificação bioquímica através das provas do IMViC: produção de indol (I), de Vermelho de Metila (VM), de Voges-Proskauer (VP) e de citrato $(C)$. Após a identificação positiva, foi utilizada à tabela de Número Mais Provável para calcular o NMP/g.

\subsection{QUANTIFICAÇÃO DE STAPHYLOCOCCUS COAGULASE POSITIVA}

Foram utilizadas as diluições seriadas de $10^{-1}$ a $10^{-3}$, sendo retirados $0,1 \mathrm{~mL}$ e depositados em placas de petri contendo ágar Baird-Parker. Em seguida, a distribuição do inóculo as placas foram incubadas a 35드/24 a $48 \mathrm{~h}$. Posteriormente, as placas que continham de 25 a 250 colônias, foi observado se haviam colônias negras, brilhantes, com zona de precipitação ao redor e circundadas ou não por halo claro, em caso positivo, foram retiradas cinco colônias de cada placa, sendo semeadas em tubos contendo ágar nutriente inclinado e incubadas a $35^{\circ} \mathrm{C}$ a $24 \mathrm{~h}$. Após esse tempo foi realizada a prova de coagulase livre com plasma de coelho citratado. O resultado final da contagem de Staphylococcus coagulase positivo foi expresso em Unidades Formadoras de Colônias (UFC/g). As análises foram realizadas em duplicata.

\subsection{ENUMERAÇÃO DE BOLORES E LEVEDURAS}

Foram separadas as diluições seriadas de $10^{-1}$ a $10^{-3}$, e realizada a semeadura por superfície em placas de petri contendo Ágar Dicloran Rosa de Bengala Cloranfenicol (DRBC), as placas foram colocadas a temperatura ambiente de $25^{\circ} \mathrm{C} / 5$ dias. Foram selecionadas as placas contendo de 15 a 150 colônias, sendo realizada assim a contagem das Unidades Formadores de Colônias (UFC/g). As análises foram realizadas em duplicata.

\subsection{DETERMINAÇÃO DO POTENCIAL HIDROGENIÔNICO (PH)}

RC: 81950

Disponível em: https://www.nucleodoconhecimento.com.br/nutricao/parmesao-ralado 
Em um béquer de $50 \mathrm{~mL}$ foi pesada $10 \mathrm{~g}$ da amostra do queijo, adicionando em seguida $20 \mathrm{~mL}$ de água destilada. Após homogeneização, $\mathrm{o} \mathrm{pH}$ foi medido diretamente pela inserção do eletrodo, utilizando-se potenciômetro digital TECNAL, modelo TEC-2MP. Análises foram realizadas em triplicata.

\section{RESULTADOS E DISCUSSÃO}

A Tabela 1 apresenta os resultados das análises para Staphylococcus coagulase positivo, bolores e leveduras e Escherichia coli.

Tabela 1. Resultados das análises microbiológicas do queijo parmesão ralado comercializado em supermercados na cidade de Maceió/AL.

\begin{tabular}{|c|c|c|c|}
\hline $\begin{array}{l}\text { Marcas } \\
\text { comerciais }\end{array}$ & $\begin{array}{l}\text { Eschericia coli } \\
(\mathrm{NMP} / \mathrm{g})\end{array}$ & $\begin{array}{l}\text { Staphylococcus coagulase } \\
+(\mathrm{UFC} / \mathrm{g})\end{array}$ & $\begin{array}{l}\text { Bolores } \quad \text { e } \\
\text { Leveduras (UFC/g) }\end{array}$ \\
\hline A & $<3$ & $<1$ & $<1$ \\
\hline B & $<3$ & $<1$ & $<1$ \\
\hline C & $<3$ & $<1$ & $<1$ \\
\hline D & $<3$ & $<1$ & $<1$ \\
\hline E & $<3$ & $<1$ & $<1$ \\
\hline $\mathrm{F}$ & $<3$ & $1,2 \times 10^{4}$ & $<1$ \\
\hline G & $<3$ & $4,5 \times 10^{2^{*}}$ & $<1$ \\
\hline $\mathrm{H}$ & $<3$ & $2 \times 10^{2^{*}}$ & $<1$ \\
\hline I & $<3$ & $<1$ & $<1$ \\
\hline $\mathrm{J}$ & $<3$ & $<1$ & $<1$ \\
\hline K & $<3$ & $<1$ & $<1$ \\
\hline L & $<3$ & $6,2 \times 10^{3^{*}}$ & $<1$ \\
\hline M & $<3$ & $<1$ & $<1$ \\
\hline
\end{tabular}

UFC: Unidades Formadoras de colônias. NMP: Número Mais Provável. *: estimado. Fonte: autor.

RC: 81950

Disponível em: https://www.nucleodoconhecimento.com.br/nutricao/parmesao-ralado 
A Instrução Normativa $n^{\circ}$ 60, de 23 de dezembro de 2019, estabelece para o queijo ralado um limite máximo de $10^{2} \mathrm{UFC} / g$ para Staphylococcus coagulase positiva e Bolores e leveduras, e para a Escherichia coli o valor de $10^{2} \mathrm{NMP} / \mathrm{g}$ (BRASIL, 2019).

$\mathrm{Na}$ Tabela 1, observa-se que 30,7\% $(n=4)$ das 13 amostras analisadas apresentaram a presença do Staphylococcus coagulase positivo com valores acima do permitido pela legislação, porém 100\% $(n=13)$ das amostras não apresentaram crescimento para Escherichia coli e bolores e leveduras.

Os valores encontrados para Staphylococcus coagulase positivo estão próximos ao do estudo realizado por Salvador et al. (2001), que encontraram em quatro amostras de queijo tipo parmesão ralado valores entre $10^{3}$ e $10^{4} \mathrm{UFC/g}$. Esses resultados são preocupantes, uma vez que a enterotoxina termoestável produzida pelos estafilococos coagulase positivo é responsável por intoxicações alimentares, resultando em gastrenterite quando sua população atinge o número de $10^{5} \mathrm{UFC} / \mathrm{g}$.

Os resultados encontrados para Escherichia coli foram semelhantes com os de Pimentel et al. (2002) e Maldonado et al. (2006), e diferentes com os obtidos por Salvador et al. (2001) que relataram contaminação em quatro amostras de queijo parmesão por essa bactéria.

A ausência da bactéria Escherichia coli nos alimentos é sempre positiva pois sua presença é um indicador de contaminação fecal uma vez que ela tem como habitat exclusivo o intestino de seres humanos e animais de sangue quente sugerindo, práticas higiênico-sanitárias insatisfatórias (JAY, 2005).

Nas análises microbiológicas realizadas, $100 \%$ das amostras apresentaram ausência de bolores e leveduras, esses resultados diferem de outros encontrados na literatura como o de Mattar et al. (2011), que analisaram queijo tipo parmesão ralado no Estado de Minas Gerais e encontraram $77 \%$ das amostras contaminadas por bolores. De acordo com Abreu et al. (2010), em outro estudo realizado também em

RC: 81950

Disponível em: https://www.nucleodoconhecimento.com.br/nutricao/parmesao-ralado 
Minas Gerais, encontraram em 18\% das amostras analisadas contaminação com valores de $10^{3} \mathrm{UFC} / \mathrm{g}$ para bolores e leveduras.

O crescimento de bolores e leveduras nos alimentos pode indicar informações importantes, como condição sanitária insatisfatória de equipamentos e utensílios e multiplicação no produto sugestivo de falhas na cadeia produtiva e/ou estocagem e matéria prima com contaminação inicial excessiva (SILVA et al., 2017).

A vida de prateleira dos alimentos está diretamente relacionada à capacidade de sobrevivência ou de multiplicação dos micro-organismos neles contidos, sendo essa capacidade controlada por fatores intrínsecos (ex: atividade de água $(A w)$, potencial hidrogeniônico $(\mathrm{pH})$, etc.) e/ou extrínsecos (ex: temperatura e umidade do ambiente, etc.) (VASCONCELOS; FILHO, 2010).

Cecchi (2003) relata que o pH tem sido um fator intrínseco frequentemente analisado em diversos estudos relacionados a qualidade microbiológica dos alimentos de origem animal, visto que ele interfere tanto para inibir como acelerar o crescimento microbiano. O queijo tipo parmesão tem a seguinte composição: umidade (32\% a 34\%), $\mathrm{pH}(5,3 \%$ a $5,5 \%)$, gordura total $(22 \%$ a $24 \%)$ e cloreto de sódio (2,0\% a 3,5\%) (SILVA, 2005).

Tabela 2. Resultados dos valores do potencial hidrogeniônico (pH) e Sódio encontrados nas amostras de queijo parmesão ralado comercializado em supermercados na cidade de Maceió.AL.

\begin{tabular}{|l|l|l|}
\hline $\begin{array}{l}\text { Marcas } \\
\text { comerciais }\end{array}$ & $\mathrm{pH}$ & Sódio $(\mathrm{mg})$ \\
\hline A & 5,61 & 74 \\
\hline B & 5,37 & 153 \\
\hline C & 5,14 & 168 \\
\hline D & 5,33 & 62 \\
\hline E & 5,37 & 623 \\
\hline
\end{tabular}

RC: 81950

Disponível em: https://www.nucleodoconhecimento.com.br/nutricao/parmesao-ralado 


\begin{tabular}{|l|l|l|}
\hline F & 5,37 & 100 \\
\hline G & 5,52 & 100 \\
\hline H & 5,47 & 45 \\
\hline I & 5,22 & 90 \\
\hline J & 5,15 & 138 \\
\hline K & 5,48 & 146 \\
\hline L & 5,48 & 186 \\
\hline M & 5,46 & 187 \\
\hline
\end{tabular}

Fonte: autor.

De acordo com a tabela 2, que os valores de $\mathrm{pH}$ variaram entre 5,14 e 5,61, sendo considerados alimentos pouco ácidos, podendo favorecer o crescimento de microorganismos. Embora os valores de $\mathrm{pH}$, encontrados nas análises sejam considerados pouco ácidos, os altos valores de sódio reduzem de maneira significativa a atividade de água, diminuindo as chances de crescimento microbiano (GERMANO; GERMANO, 2019).

Embora tenha ocorrido crescimento de Staphylococcus coagulase positiva em $30,7 \%(n=4)$ das amostras, este resultado pode ser explicado, pois segundo Franco e Landgraf (2008), a maioria das bactérias patogênicas requerem Aw maior do que 0,9, no entanto, Staphylococcus aureus pode crescer em Aw tão baixa quanto 0,86. Provavelmente a condição favorável para crescimento, aliada também a uma contaminação inicial oriunda da matéria prima ou durante o processamento podem ter contribuído de forma significativa para o crescimento desse micro-organismo nas amostras.

Em relação aos teores de sódio encontrados na rotulagem das marcas comerciais do atual estudo, foi verificada na tabela 2 uma variação de 45 a $623 \mathrm{mg} / 10 \mathrm{~g}$ (equivalente a colher de sopa) de queijo parmesão ralado. Observa-se grande diferença do teor de sódio (623 mg) da marca comercial E em comparação as outras

RC: 81950

Disponível em: https://www.nucleodoconhecimento.com.br/nutricao/parmesao-ralado 
marcas. É importante salientar que a amostra $E$ é o único queijo com adição de lactose.

Na fabricação do queijo tipo parmesão, a etapa da salga é utilizada para controlar a maturação, que é uma etapa onde ocorre entre outros fatores uma redução considerável da lactose pelas bactérias presente no fermento. Normalmente a maturação do queijo parmesão leva de 6 a 18 meses (SILVA, 2005).

A explicação provável para esses altos valores de sódio na amostra E, pode ser que, para reduzir teores maiores da lactose, essa marca comercial tenha utilizado um maior tempo de maturação e consequentemente $o$ da salga, aumentando consideravelmente a quantidade de sódio.

De acordo com a Tabela Brasileira de Composição de Alimentos - TACO (NEPAUNICAMP, 2011), 10 gramas de queijo parmesão ralado (1 colher de sopa) contêm $255 \mathrm{mg}$ de sódio, sendo considerado um valor bastante alto se comparado com a quantidade em grama do alimento.

Alimentos sólidos com mais de $200 \mathrm{mg}$ de sódio/100 g do produto são considerados ricos em sódio e, portanto, devem ser consumidos com moderação (ABIC, 2009). Portanto, com base nessa informação, observa-se que 100\% das amostras deste estudo apresentaram valores de sódio acima de $200 \mathrm{mg}$, visto que os valores de sódio na tabela 2 são para a porção de $10 \mathrm{~g}$ na rotulagem do produto.

Com os resultados encontrados, sugere-se que o valor do sódio presente no queijo parmesão ralado pode ter influenciado no controle do crescimento microbiano, e que provavelmente nas amostras com crescimento bacteriano podem ter ocorrido falhas no processo.

\section{CONCLUSÃO}

A pesquisa considera que a contaminação microbiologia é limitada, porém, tem maior susceptibilidade ao crescimento por Staphylococcus sp., uma vez que, estes

RC: 81950

Disponível em: https://www.nucleodoconhecimento.com.br/nutricao/parmesao-ralado 
podem ser veiculados através da mastite, doença causada pela bactéria $S$. aureus, sendo preocupante, uma vez que esses micro-organismos produzem uma enterotoxina termoestável que pode acarretar intoxicação alimentar, o que representa um risco para saúde pública.

A atenção dos fabricantes de queijo tipo parmesão ralado, no controle do processo, que vai desde a coleta da matéria prima até a distribuição para comercialização é de fundamental importância, visto que, um processo tecnológico bem executado contribui para um produto final de qualidade sanitária e físico-química adequado.

\section{REFERÊNCIAS}

ABReU, A. N. I.; BAtISTA, L. R.; ABREU, L. R.; PINTO, S. M.; PEADO, G.; OLIVEIRA, M. S. Qualidade Microbiológica de Queijo Ralado Comercializado no

Estado de Minas Gerais, XIX Congresso de Pós-Graduação da UFLA, 2010.

ASSOCIAÇÃO BRASILEIRA DAS INDÚSTRIAS DE QUEIJOS (ABIQ). Queijos no Brasil. 2009.

Disponível em:

http://www.abiq.com.br/nutricao_queijosbrasil_ant.asp>. Acesso em: 31/10/2019.

BRASIL- Instrução Normativa $n^{\circ}$ 60, de 23 de dezembro de 2019. Estabelece as listas de padrões microbiológicos para alimentos. Diário Oficial da República Federativa do Brasil, Brasília. Publicado em: 26/12/2019 | Edição: 249 Seção: 1. Página: 133.

em:

<http://portal.anvisa.gov.br/documents/10181/4660474/IN_60_2019_.pdf/8b764b8f5172-4bfc-a855-bc73972ee96f>. Acesso em 17/01/2019.

$\mathrm{CECCHI}, \mathrm{H}$. M. Fundamentos teóricos e práticos em análises de alimentos. 2. ed. Campinas: Editora da Unicamp, 2003.

FRANCO, B. D. G. M.; LANDGRAF, M. Microbiologia dos alimentos. São Paulo: Atheneu, 2008.

RC: 81950

Disponível em: https://www.nucleodoconhecimento.com.br/nutricao/parmesao-ralado 
FURTADO, M. M. Principais problemas dos queijos: causas e prevenção. 2 ed. São Paulo: Fonte Comunicações e Editora, 2005.

GERMANO, P. M. L.; GERMANO, M. I. S. Higiene e vigilância sanitária de alimentos. Editora: MANOLE. 6 e edição. pág. 896, 2019.

HOFFMANN, F. L; GONÇALVES, T. M. V.; COELHO, A. R.; HIROOKA, E. Y.; HOFFMANN, P. Qualidade microbiológica de queijos ralados de diversas marcas comerciais, obtidos do comércio varejista do município de São José do Rio Preto, SP. Revista Higiene Alimentar, São Paulo, v. 18, n. 122, p. 62-66, jul. 2004

INSTITUTO ADOLFO LUTZ. Métodos químicos e físicos para análise de alimentos. 3 a ed. São Paulo. Normas analíticas do Instituto Adolfo Lutz. V. 1, 1985.

JAY, J.M. Microbiologia de alimentos. Porto Alegre: Ed. Artmed. ed. 6ª 2005.

JUSTUS, A.; FERRARI, L. M. B.; RODRIGUES, L. R.; FERREIRA, M. L.; PINTO S. M.; ABREU, L. R. Caracterização física e química de queijos parmesão ralado comercializados na região sul de Minas Gerais. Minas Gerais, Revista Instituto Laticínio Cândido Tostes, № 379, p. 16-24, 2011.

MALDONADO, A. G.; MENICI, A.; P.; BALIAN, S. C.; TELLES, E. O. Avaliação higiênico-sanitária de amostras de queijo parmesão ralado do município de São Paulo, SP. Higiene Alimentar, São Paulo, v. 20, n. 141, p. 103-105, 2006.

MARTIN, N.H.; TRMČIĆ, A.; HSIEH, T.H.; BOOR, K.J.; WIEDMANN, M. The Evolving Role of Coliforms as Indicators of Unhygienic Processing Conditions in Dairy Foods. Frontiers in microbiology, v. 7, 2016.

MAtTAR, T. V.; ABREU, A. N. I.; ABREU, L. R.; BATISTA, L. R. Análise da qualidade microbiológica de queijo ralado. In: XXIV Congresso de Iniciação Científica da Universidade Federal de Lavras, 2011.

RC: 81950

Disponível em: https://www.nucleodoconhecimento.com.br/nutricao/parmesao-ralado 
NEPA-UNICAMP. Tabela brasileira de composição de alimentos. 4. ed. Campinas: UNICAMP.161 p 2011.

PIMENTEL, E.F.; DIAS, R.S.; RIBEIRO-CUNHA, M.; GLÓRIA, M.B.A. Evalution of the labelling and physico-chemical and microbiological quality of grated cheese. Ciência e Tecnologia de Alimentos, Campinas, v.22, n.3, 2002.

PINTO, M.S.; FERREIRA, C. L. L. F.; MARTINS, J. M.; TEODORO, V. A. M.; PIRES, A.C.C.; FONTES,L.B.A.; VARGAS,AP.I.P. Segurança alimentar do queijo Minas artesanal do serro, Minas Gerais, em função da adoção de boas práticas de fabricação. Pesquisa Agropecuária Tropical, Goiania, v. 39, n.4, p. 342-347, out. 2009.

RIEDEL, G. Controle sanitário dos alimentos. São Paulo: Atheneu, 455 p. 2005.

SALVADOR, M.; CAMASSOLA, M.; MOSCHEN, E.; ZANROSSO, A. Avaliação da qualidade microbiológica de queijo prato e parmesão ralado. Boletim do Centro de Pesquisa de Processamento de Alimentos, Curitiba, v.19, n.1, p.65-74, 2001.

SILVA, F. T. Queijo parmesão. (Agroindústria Familiar). Brasília, DF: Embrapa Informação Tecnológica, 2005.

SILVA, N.; JUNQUEIRA, V.C.A.; SILVEIRA, N.F.A.; TANIWAKI. M.H.; GOMES, R.A.R.; OKAZAKI, M.M. Manual de Métodos de Análise Microbiológica de Alimentos e Água. 5 ed. São Paulo: Livraria Varela, 2017.

VASCONCELOS, M.A.S.; FILHO, A. B. M. Conservação de alimentos. Recife: EDUFRPE. 130p. 2010.

Enviado: Novembro de 2020.

Aprovado: Abril de 2021.

RC: 81950

Disponível em: https://www.nucleodoconhecimento.com.br/nutricao/parmesao-ralado 